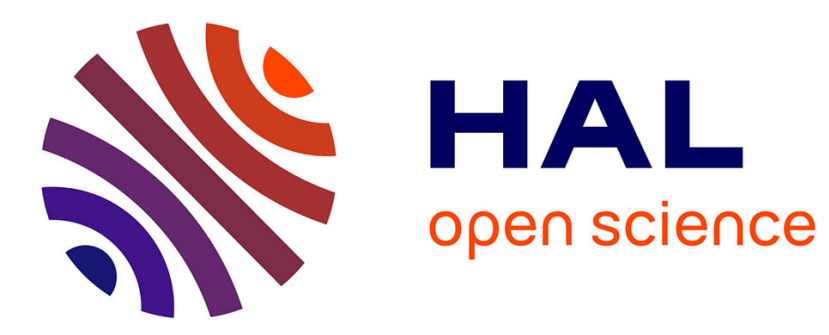

\title{
Effect of the Dielectric and Mechanical Properties of the Polymer Matrix on ZnO-Nanowire-Based Composite Nanogenerators Performance
}

\author{
Nicole Doumit, Guylaine Poulin-Vittrant
}

\section{To cite this version:}

Nicole Doumit, Guylaine Poulin-Vittrant. Effect of the Dielectric and Mechanical Properties of the Polymer Matrix on ZnO-Nanowire-Based Composite Nanogenerators Performance. Advanced Theory and Simulations, 2020, 3 (9), pp.2000128. 10.1002/adts.202000128 . hal-02918295

\section{HAL Id: hal-02918295 \\ https://hal.science/hal-02918295}

Submitted on 20 Aug 2020

HAL is a multi-disciplinary open access archive for the deposit and dissemination of scientific research documents, whether they are published or not. The documents may come from teaching and research institutions in France or abroad, or from public or private research centers.
L'archive ouverte pluridisciplinaire HAL, est destinée au dépôt et à la diffusion de documents scientifiques de niveau recherche, publiés ou non, émanant des établissements d'enseignement et de recherche français ou étrangers, des laboratoires publics ou privés. 


\title{
Effect of the Dielectric and Mechanical Properties of the Polymer Matrix on ZnO-Nanowire-Based Composite Nanogenerators Performance
}

\author{
Nicole DOUMIT, Guylaine POULIN-VITTRANT \\ GREMAN UMR 7347 CNRS, INSA Centre Val de Loire, Université de Tours, 3 rue de la \\ chocolaterie, 41034 Blois, France. \\ E-mail: nicole.doumit@univ-tours.fr; guylaine.poulin-vittrant@univ-tours.fr
}

Keywords: Vertically Integrated Nanogenerator, ZnO nanowires, piezoelectricity, mechanical energy harvesting, Finite Element Model

\begin{abstract}
The effect of Young's Modulus and dielectric permittivity of the polymer matrix in vertically integrated nanogenerators (VING) on their output performance is studied by combining Finite Element Method (FEM) and analytical modeling. To conduct this study, an elementary cell is considered, based on one $\mathrm{ZnO}$ nanowire surrounded by the polymer matrix. We demonstrate that the polymer matrix should have the lowest Young's Modulus and permittivity as possible, in order to maximize the output voltage and power. Four different materials, which have already been proposed in literature for such composite VING, are then compared: Parylene $\mathrm{C}, \mathrm{PMMA}, \mathrm{Al}_{2} \mathrm{O}_{3}$ and PDMS. Simulation results show that PDMS, who has the lowest values of both Young's Modulus and permittivity, gives the highest output performance. Finally, the sensitivity to another design parameter - the surface density of nanowires - is calculated, and this study shows that choosing a polymer material with the lowest Young's Modulus and permittivity is more powerful to improve the VING performance.
\end{abstract}

\section{Introduction}

Over the past few years, piezoelectric nanowires (NWs) have attracted interest from researchers working on mechanical energy harvesting for autonomous sensors whose market is expected to grow, with the development of the Internet of Things. ${ }^{[1-3]}$ As electroactive material within nanogenerators (NG), the piezoelectric and semiconducting NWs (usually ZnO or GaN) convert mechanical energy into electricity when strained by an external force. ${ }^{[4-7]}$ The first NG proof of concept was presented in $2006,{ }^{[8]}$ with an experiment carried out with an AFM tip sweeping across a ZnO NWs array, leading to the generation of an electric voltage. In 2008, a single ZnO NW bonded horizontally on a flexible substrate was developed: ${ }^{[9]}$ periodic bending of the substrate produced an alternative electric output from the NW. Since then, substantial progress has been made to integrate a large number of NWs together, aiming at harvesting electrical energy from all NWs simultaneously. The NG design has evolved with lateral, ${ }^{[9-11]}$ radial ${ }^{[12,13]}$ and vertical ${ }^{[11,14]}$ NWs arrays. However, the Vertically Integrated NanoGenerator (VING) is the most used NG design because its fabrication and integration are often easier, especially when the synthesis 
process leads to an array of NWs oriented orthogonally to the substrate. [5,15-17] Nanostructured materials like $\mathrm{ZnO}{ }^{[5,17,18]}, \mathrm{GaN}^{[19,20]}, \mathrm{PZT}{ }^{[21,22]}, \mathrm{BaTiO}_{3}{ }^{[23,24]}, \mathrm{NaNbO}_{3}{ }^{[25]}$ and PVDF ${ }^{[26]}$ have been used and studied as piezoelectric material within a VING. However, among them, $\mathrm{ZnO}$ is the most used material because it is lead free, biocompatible and it can be grown easily at low temperature $\left(85^{\circ} \mathrm{C}\right)$ on several substrates ${ }^{[5,8,16,18]}$, thanks to hydrothermal synthesis. Many filler materials with different properties (Table 1 ) have also been used (PMMA, $\mathrm{Al}_{2} \mathrm{O}_{3}$, PDMS, Parylene C...). ${ }^{[5,25,27]}$ The performance of some VING devices using different types of materials is presented in Table 2. Hinchet et al. ${ }^{[15]}$ have demonstrated that both the electrical potential and energy surface density could be improved by tuning the NW's density (represented by the ratio of NW diameter to the core cell width) to an optimum value, and by minimizing the thickness of the insulating layer. They also showed that PMMA was a good choice for the insulating material compared to other materials with higher Young's modulus. In another study, ${ }^{[5]}$ they divided the insulating layer in two parts: the layer above NWs and the layer between NWs. They studied and compared the performance of NGs as a function of the top insulating layer material. Three type of material were chosen $\left(\mathrm{SiO}_{2}, \mathrm{Si}_{3} \mathrm{~N}_{4}\right.$ and $\left.\mathrm{Al}_{2} \mathrm{O}_{3}\right)$, all of them presenting both a Young's modulus and dielectric permittivity higher than the interstitial insulator (PMMA). Authors proved that the usage of a high Young's modulus and permittivity for the top insulator maximizes the energy stored in the NG. However, none of the optimization research works investigated the best solution between optimizing the filler properties or optimizing the NWs' volume density (volume fraction of the piezoelectric material over the total volume of the composite layer) in order to obtain the highest generated voltage and/or power. Indeed, Young's modulus and dielectric permittivity values of the filler affect the VING performance since they influence the efficiency of the conversion of mechanical energy into electrical one. For this purpose, in this paper, the filler's Young's Modulus and permittivity were varied successively in order to obtain the most efficient VING, and this theoretical study was performed using HyMeSoVING method. ${ }^{[27]}$ We show that the lower the filler's Young's modulus and permittivity, the higher the generated voltage and power. These results are compared to the increase in performance obtained when the NW's volume density is optimized.

Table 1: Young's modulus and relative dielectric permittivity of commonly used fillers

\begin{tabular}{|c|c|c|c|c|}
\hline Filler material & PDMS & Parylene C & PMMA & $\mathbf{A l}_{\mathbf{2}} \mathbf{O}_{\mathbf{3}}$ \\
\hline $\begin{array}{c}\text { Young's Modulus } \\
Y\end{array}$ & $360-870 \mathrm{kPa}{ }^{[28]}$ & $2.4-4 \mathrm{GPa}^{[29]}$ & $2-4.5 \mathrm{GPa}^{[30,31]}$ & $345-409 \mathrm{GPa}{ }^{[32,37]}$ \\
\hline $\begin{array}{c}\text { Relative dielectric } \\
\text { permittivity } \epsilon_{11}^{F}\end{array}$ & $2.5-3^{[33]}$ & $2.7-6^{[34]}$ & $2.85-3.6^{[35,36]}$ & $5.7-10^{[37,38,39]}$ \\
\hline
\end{tabular}


Table 2: State of the art on NGs performance

\begin{tabular}{|c|c|c|c|c|c|c|c|c|}
\hline $\begin{array}{c}\text { NW } \\
\text { Material }\end{array}$ & $\begin{array}{c}\text { Filler } \\
\text { material }\end{array}$ & $\begin{array}{c}\text { NW } \\
\text { diameter }\end{array}$ & $\begin{array}{l}\text { NW } \\
\text { length }\end{array}$ & $\begin{array}{c}\text { Number } \\
\text { of NWs or } \\
\text { NW's } \\
\text { density }\end{array}$ & $\begin{array}{l}\text { Applied force } \\
\text { or pressure }\end{array}$ & $\begin{array}{l}\text { Open- } \\
\text { circuit } \\
\text { voltage }\end{array}$ & $\begin{array}{c}\text { Maximum } \\
\text { power or } \\
\text { power } \\
\text { density }\end{array}$ & Reference \\
\hline ZnO & PMMA & $50 \mathrm{~nm}$ & $600 \mathrm{~nm}$ & 1 & $\begin{array}{c}1 \mathrm{MPa} \\
\text { (compression) }\end{array}$ & $80 \mathrm{mV}$ & - & {$[5]$} \\
\hline ZnO & - & $4 \mu \mathrm{m}$ & $200 \mu \mathrm{m}$ & 1 & $\begin{array}{l}\text { Bending of the } \\
\text { substrate }\end{array}$ & $50 \mathrm{mV}$ & - & [9] \\
\hline $\mathrm{ZnO}$ & PMMA & $4 \mu \mathrm{m}$ & $400 \mathrm{~nm}$ & 9 & $\begin{array}{c}- \\
\text { (compression) }\end{array}$ & $15 \mathrm{mV}$ & $\begin{array}{c}2.8 \\
\mathrm{nW} / \mathrm{cm}^{2} \\
\end{array}$ & [40] \\
\hline $\mathrm{ZnO}$ & $\mathrm{Si}_{3} \mathrm{~N}_{4}$ & $\sim 100 \mathrm{~nm}$ & $5 \mathrm{~nm}$ & 1 & $\begin{array}{c}- \\
\text { (compression) }\end{array}$ & $25 \mathrm{mV}$ & - & [11] \\
\hline $\mathrm{ZnO}$ & $\begin{array}{c}\text { Parylene } \\
\text { C } \\
\end{array}$ & $50 \mathrm{~nm}$ & $0.5 \mu \mathrm{m}$ & $\begin{array}{c}100 \\
\mathrm{NW} / \mu \mathrm{m}^{2}\end{array}$ & $\begin{array}{c}13 \mathrm{~N} \\
\text { (compression) }\end{array}$ & $9 \mathrm{~V}$ & - & [16] \\
\hline GaN & HSQ & $45 \mathrm{~nm}$ & $1 \mu \mathrm{m}$ & $\begin{array}{c}10^{9} \\
\mathrm{NWs} / \mathrm{cm}^{2}\end{array}$ & $\begin{array}{c}149 \mathrm{nN} \\
\text { (compression) }\end{array}$ & $350 \mathrm{mV}$ & $\begin{array}{c}12.7 \\
\mathrm{~mW} . \mathrm{cm}^{-3}\end{array}$ & [41] \\
\hline $\begin{array}{c}\mathrm{ZnO}+ \\
\text { multiwall- } \\
\text { carbon } \\
\text { nanotubes }\end{array}$ & PDMS & $30 \mathrm{~nm}$ & $50 \mu \mathrm{m}$ & - & $\begin{array}{l}\text { Hammer } \\
\text { knocking }\end{array}$ & $7.5 \mathrm{~V}$ & $18.75 \mu \mathrm{W}$ & [42] \\
\hline $\begin{array}{c}\mathrm{ZnO}+ \\
\text { multiwall- } \\
\text { carbon } \\
\text { nanotubes }\end{array}$ & PDMS & $30 \mathrm{~nm}$ & $50 \mu \mathrm{m}$ & - & Foot stamp & $30 \mathrm{~V}$ & - & [42] \\
\hline $\mathrm{ZnO}$ & $\mathrm{Al}_{2} \mathrm{O}_{3}$ & $200 \mathrm{~nm}$ & $3.5 \mu \mathrm{m}$ & - & Bending & $2.1 \mathrm{~V}$ & - & [43] \\
\hline
\end{tabular}

\section{Theory}

A VING can be described as a multi-layer device: First, the core of the structure consists on ZnO NWs array that converts mechanical energy into electrical energy via piezoelectric effect. Secondly, this NWs array is coated with an insulating layer which increases mechanical robustness and protects it from the electrical leakages and short circuits that could occur. ${ }^{[16]}$ The third part is the top and bottom electrodes which are used to collect electrical charges. The principle of the mechanical energy harvesting with the VING device is the following: the applied mechanical forces compress the NWs along their z-axis. This compression generates a voltage difference across NWs due to the piezoelectric effect: negative charges appear at the top of the NWs and positive charges appear at the bottom electrode. The polarizationinduced electric field drives a flow of electrons through the external circuit. A reverse flow of electrons occurs when the compression onto the VING decreases and the VING returns to the initial state.

HyMeSoVING (Hybrid Method for Simulation of VING) ${ }^{[27]}$, a combination of a Finite Element (FE) model and an analytical model, is described in Figure 1: on one hand, the open-circuit voltage $\left(V_{O C}\right)$ delivered by an elementary cell of the VING is calculated using FE analysis (here using COMSOL Multiphysics ${ }^{\circledR}$ software); on the other hand, the optimum resistive load ( $R_{\text {opt }}$ ) of this elementary nanogenerator cell is estimated thanks to an equivalent electrical circuit 
(Figure 1) whose parameters are homogenized ones, considering the active layer as a 1-3 piezocomposite. Using both results ( $V_{o c}$ and $\left.R_{o p t}\right)$, the maximum average power delivered by the cell is then calculated. Finally, the performance of a full VING can then be deduced from the elementary cell's results by using the total number of NWs within the VING, as a scaling factor.

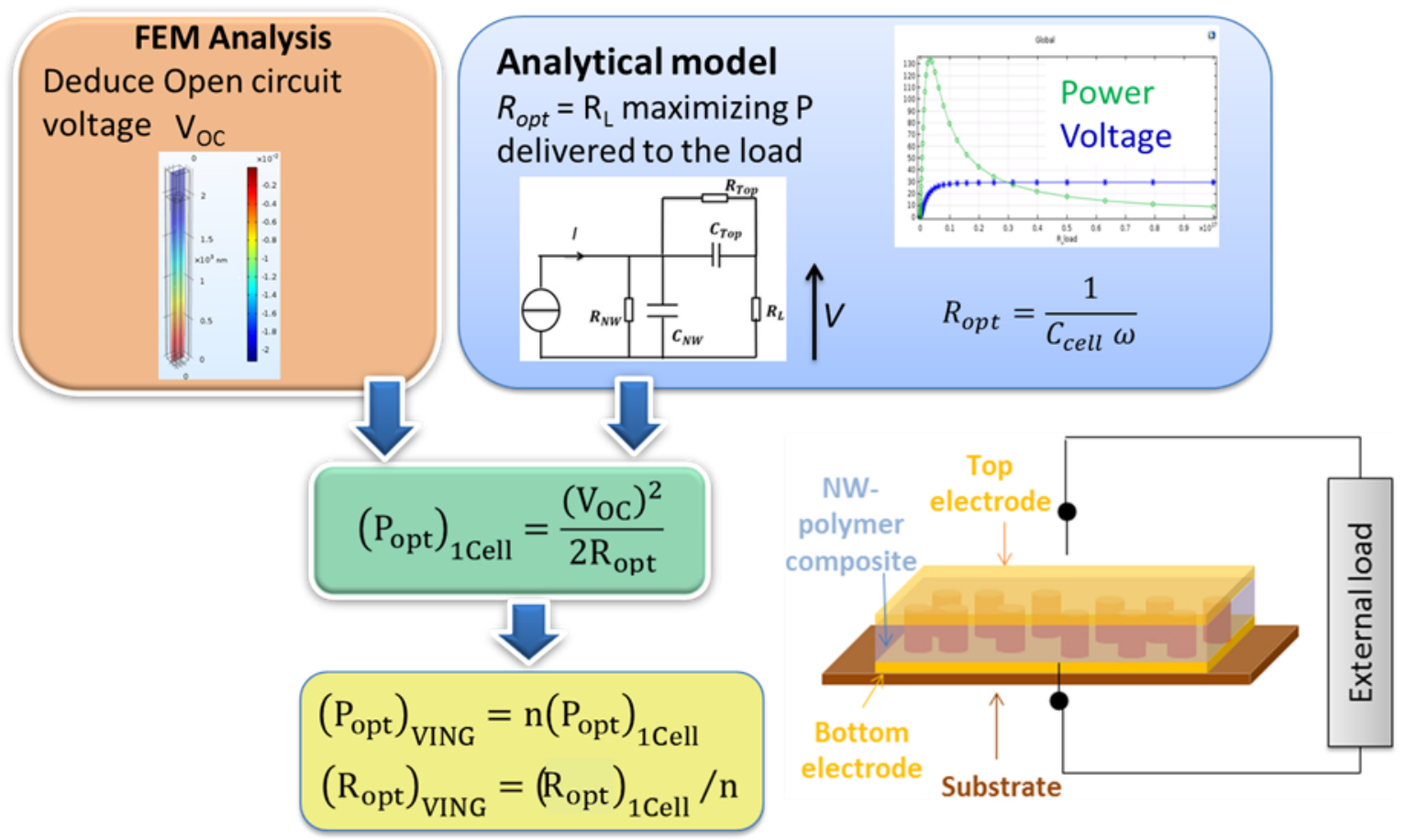

Figure 1: HyMeSoVING (Hybrid Method for Simulation of VING) schematic diagram.

Please note the elementary cell is composed of one ZnO NW (Figure 2.a) surrounded by the insulating matrix. Symmetry conditions are applied on the lateral edges, both in Solid Mechanics and Electrostatics modules used in COMSOL. In Solid Mechanics module, one symmetry condition is sufficient for all lateral edges, whereas in Electrostatics module two periodic conditions must be defined, one for $x$-axis edges and a second one for $y$-axis edges. The cell is clamped at the bottom face and a vertical surface force $F$ is applied onto the top face.

The polymer matrix material is assumed to be purely elastic and dielectric. Therefore, its behavior is governed by Hooke's law and Poisson's equation:

$T=c S$

$\nabla \cdot D=\rho_{V}$

where $\mathrm{T}$ is the stress tensor, $\mathrm{S}$ is the strain tensor, $\mathrm{c}$ is the stiffness tensor, $\mathrm{D}$ is the electrical displacement field and $\rho_{V}$ is the volume charge density. 
The NWs are considered as pure piezoelectric material. Therefore, electrical and mechanical laws are coupled, through the linear piezoelectric constitutive equations:

$T=c_{E} S-e^{t} E$

$D=e S-\epsilon E$

where $c_{E}$ is the stiffness tensor for a constant electrical field $\boldsymbol{E}, e$ is the piezoelectric coupling tensor in stress-charge notation and $\boldsymbol{\epsilon}$ is the electric permittivity tensor. The superscript $t$ stands for the transpose of the matrix.

In the case of $\mathrm{ZnO}$ based devices, the piezocomposite can be described as a 1-3 composite (1D piezoelectric rods in a 3D insulating matrix). Smith and Auld ${ }^{[44]}$ showed that the constitutive relations can be written as:

$\overline{T_{3}}=\bar{c}_{33}^{E} \bar{S}_{3}-\bar{e}_{33} \bar{E}_{3}$

$\bar{D}_{3}=\bar{e}_{33} \bar{S}_{3}+\bar{\epsilon}_{33}^{S} \bar{E}_{3}$

where

$\bar{c}_{33}^{E}=\delta\left(c_{33}^{E}-\frac{2(1-\delta)\left(c_{13}^{E}-c_{12}^{F}\right)^{2}}{\delta\left(c_{11}^{F}+c_{12}^{F}\right)+(1-\delta)\left(c_{11}^{E}+c_{12}^{E}\right)}\right)+(1-\delta) c_{11}^{F}$

$\bar{e}_{33}=\delta\left(e_{33}-\frac{2(1-\delta) e_{31}\left(c_{13}^{E}-c_{12}^{F}\right)}{\delta\left(c_{11}^{F}+c_{12}^{F}\right)+(1-\delta)\left(c_{11}^{E}+c_{12}^{E}\right)}\right)$

$\bar{\epsilon}_{33}^{S}=\delta\left(\epsilon_{33}^{S}+\frac{2(1-\delta) e_{31}^{2}}{\delta\left(c_{11}^{F}+c_{12}^{F}\right)+(1-\delta)\left(c_{11}^{E}+c_{12}^{E}\right)}\right)+(1-\delta) \epsilon_{11}^{F}$

where superscript F stands for filler, superscript $S$ stands for constant strain, superscript $E$ stands for constant electric field and $\delta$ is the volume fraction of the piezoelectric material over the total volume of the composite layer, $c_{11}^{F}$ and $c_{12}^{F}$ are expressed using the constitutive equations for an isotropic material as follows: ${ }^{[45]}$

$$
\begin{aligned}
c_{11}^{F} & =\frac{Y \cdot(1-\eta)}{(1+\eta) \cdot(1-2 \eta)} \\
c_{12}^{F} & =\frac{Y \cdot \eta}{(1+\eta) \cdot(1-2 \eta)}
\end{aligned}
$$


where $\mathrm{Y}$ represents the filler Young's Modulus and $\eta$ its Poisson ratio.

Passive components of the equivalent electrical circuit are calculated using the following equations: ${ }^{[27]}$

$C_{N W}=\frac{A \bar{\epsilon}_{33}^{S}}{L_{N W}}$

$C_{\text {Top }}=\frac{A \epsilon_{11}^{F}}{L_{T o p}}$

$C_{\text {Cell }}=\frac{C_{N W} C_{T o p}}{C_{T o p}+C_{N W}}$

where $\mathrm{A}$ is the cell cross-sectional area, $L_{N W}$ the NW length, $L_{T o p}$ the thickness of the insulating layer on top of the NW as shown in Figure 1.

In our previous works, ${ }^{[27]}$ we have demonstrated that the maximum average power is equal to:

$P_{o p t}=\frac{\left(V_{O C}\right)^{2}}{2 R_{o p t}}$

where $V_{O C}$ is the root mean square (rms) value of the open-circuit voltage and $R_{o p t}$ is the optimum resistance of the unit cell:

$R_{\text {opt }}=\frac{1}{C_{\text {Cell } \cdot \omega}}$

with $C_{\text {Cell }}$ the capacitance of the unit cell which is given by the following expression as a function of the NWs capacitance $C_{N W}$ and the top insulator capacitance $C_{T o p}$ :

$C_{\text {Cell }}=\frac{C_{N W} C_{T o p}}{C_{N W}+C_{T o p}}$

HyMeSoVING (Hybrid Method for Simulation of VING) will be used in order to evaluate the sensitivity of VING performance to the values of Young's modulus and dielectric permittivity of the filler, compared with the NWs volume fraction. The final objective is to provide guidelines on the best approach to optimize the VING device. 


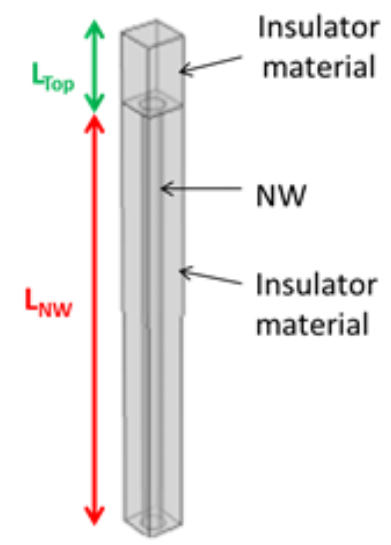

(a)

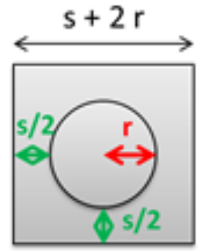

(b)

Figure 2: (a) Elementary cell including one ZnO nanowire surrounded by an insulating filler material; (b) Transversal cut of the elementary cell.

\section{Results and discussions}

\subsection{Geometrical and physical properties of the unit cell}

For the present study, and as in our previous works, ${ }^{[27]}$ we consider $\mathrm{ZnO}$ NWs with a radius $r$ of $50 \mathrm{~nm}$ and a length $\mathrm{L}_{\mathrm{NW}}$ of $1.98 \mu \mathrm{m}$. The NWs are surrounded by a polymer matrix of Parylene $\mathrm{C}$ with a residual thickness $\mathrm{L}_{\text {Top }}$ of $300 \mathrm{~nm}$ on top of the NWs. The spacing $\mathrm{S}$ between neighbor NWs is set to $70 \mathrm{~nm}$ (Figure 2.b), corresponding to a NW volume fraction

$\delta$ of $27 \%$. Dielectric loss factor of Parylene $C$ is set as isotropic one, with a value of $0.2 \%$. ${ }^{[46]}$ Electrodes are simulated as equipotential surfaces, which mean that a floating potential is assigned to the top electrode and ground to the bottom one. A mechanical boundary load is set on the top boundary at $-5 \mathrm{~N} / \mathrm{cm}^{2}$, corresponding to usual experimental tests performed on the dedicated test bench. ${ }^{[16,17]}$ The top electrode is implemented as a rigid connector in order to ensure the homogeneity of the applied load at the top surface of the cell. The mechanical boundary between the NWs and the polymer matrix is considered as ideal: thus, there is neither shear stress nor sliding movement between $\mathrm{ZnO} N W$ and the polymer matrix. An harmonic analysis is performed for an excitation frequency of $5 \mathrm{~Hz}$ because ambient sources are usually low, below $200 \mathrm{~Hz}{ }^{[47]}$ which is very far from the natural resonance frequency of the NWs (in the $\mathrm{MHz}$ range). ${ }^{[48]}$

The materials properties used for the following simulations are in the library of COMSOL Multiphysics:

- Stiffness tensor of ZnO: 


$$
\mathrm{c}_{\mathrm{ij}}^{\mathrm{E}}=\left[\begin{array}{cccccc}
2.09714 & 1.2114 & 1.05359 & 0 & 0 & 0 \\
1.2114 & 2.09714 & 1.05359 & 0 & 0 & 0 \\
1.05359 & 1.05359 & 2.11194 & 0 & 0 & 0 \\
0 & 0 & 0 & 0.42373 & 0 & 0 \\
0 & 0 & 0 & 0 & 0.42373 & 0 \\
0 & 0 & 0 & 0 & 0 & 0.44248
\end{array}\right] \times 10^{11}
$$

- Coupling tensor of $\mathrm{ZnO}$ :

$\mathrm{e}_{\mathrm{ij}}=\left[\begin{array}{cccccc}0 & 0 & 0 & 0 & -0.480508 & 0 \\ 0 & 0 & 0 & -0.480508 & 0 & 0 \\ -0.567005 & -0.567005 & 1.32044 & 0 & 0 & 0\end{array}\right]$

- ZnO relative dielectric permittivity:

$$
\epsilon_{\mathrm{ij}}^{\mathrm{S}}=\left[\begin{array}{ccc}
8.5446 & 0 & 0 \\
0 & 8.5446 & 0 \\
0 & 0 & 10.204
\end{array}\right]
$$

- ZnO dielectric losses: 1\%

- Parylene C dielectric permittivity:

$$
\epsilon_{\mathrm{ij}}^{\mathrm{F}}=\left[\begin{array}{ccc}
2.95 & 0 & 0 \\
0 & 2.95 & 0 \\
0 & 0 & 2.95
\end{array}\right]
$$

- Parylene C Young's Modulus: 2.8 GPa

- Parylene C Poisson's ratio: 0.3

Moreover, even if piezoelectric constants are well known for bulk materials, their values usually differ for MEMS (Micro-Electro-Mechanical Systems) and NEMS (NanoElectro-Mechanical Systems). They depend on the material structure (thin or thick film, nanowire...) and manufacturing process (screen printing, Pulsed Laser Deposition, Vapor-Liquid-Solid deposition, hydrothermal synthesis). Moreover, at these scales, measuring directly or indirectly the piezoelectric constants is difficult, due to the substrate presence in the case of thin films ${ }^{[49]}$ or inherent to the nanometer scale of nanowires. ${ }^{[8]}$ However, Novak et al. ${ }^{[50]}$ have determined experimentally the $d_{33}$ coefficient and obtained a value of $6 p C / N$. In our simulation, based on the used $e_{i j}$ tensor, it is possible to deduce the corresponding value of $d_{33}$ coefficient by using the following formula, which is valid under one-dimensional assumption: $d_{33}=e_{33} / c_{33}$, leading to $d_{33}=5.6 \mathrm{pC} / \mathrm{N}$ which is thus conform with literature. ${ }^{[50]}$ 
By both simulation and experimental results, it has been shown that the VING performances depend significantly on the NWs volume fraction $\delta .{ }^{[5,51]}$ The present study aims at comparing the sensitivity of the VING performances (electric potential and average power) to 2 kinds of parameters: the NWs volume fraction and the filler material properties.

First, the effect of the NWs volume fraction $\delta$ is studied, considering Parylene $C$ as the filler. Figure 3 shows the open-circuit voltage and the average power as a function of $\delta$.

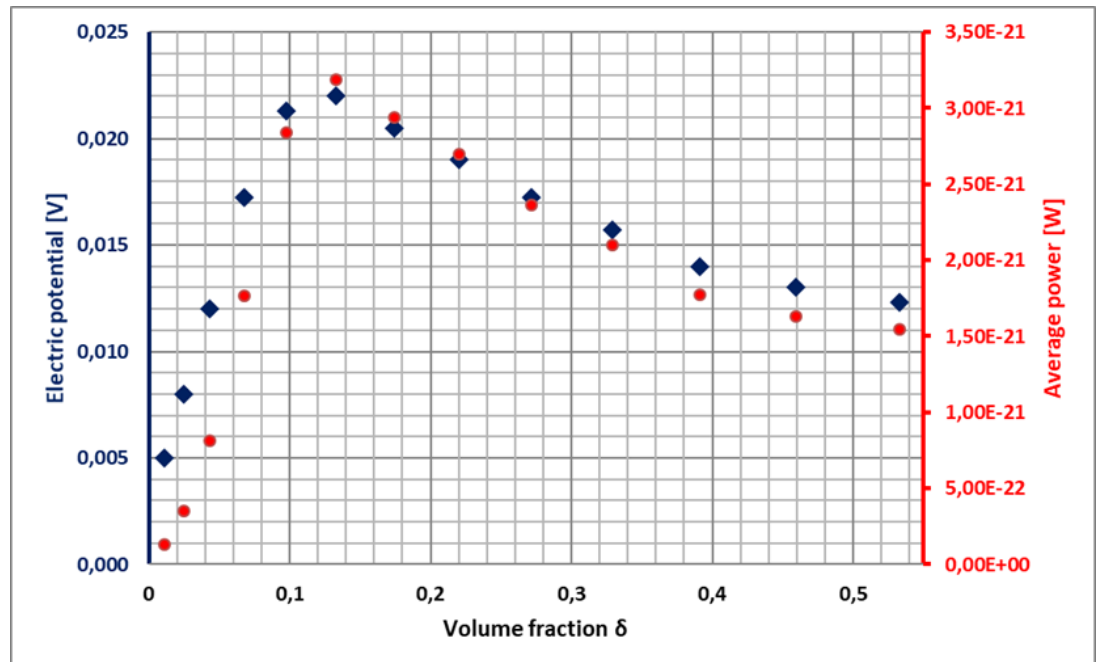

Figure 3: Open-circuit voltage and average power as a function of the volume fraction $\delta$ for a ZnO-Parylene C unit cell.

The maximum voltage $(21 \mathrm{mV})$ is obtained for $\delta$ equal to $12.5 \%$ and the maximum power $(3.21 \mathrm{zW})$ is obtained for $\delta$ equal to $13 \%$. Thus, compared to the initial value (27\%) of the volume fraction chosen in this theoretical study, ${ }^{[27]}$ the $\delta$ value maximizing the electric potential improves the latter by $28 \%$, and the $\delta$ value maximizing the average power improves the latter by $35 \%$.

In order to compare the strategies of tuning the NWs density or optimizing the filler material, four types of materials were studied as the filler in the VING elementary cell: Parylene $C, P M M A, P D M S$ and $\mathrm{Al}_{2} \mathrm{O}_{3}$. The values of both Young's modulus and permittivity of each material are presented in Table 3. Results of the four simulations performed using HyMeSoVING method are presented in Table 3. The geometrical and physical properties of the unit cell are unchanged, except the 2 above properties of the filler.

Table 3: Electrical characteristics of the VING deduced by HyMeSoVING method, as a function of the filler material

\begin{tabular}{|c|c|c|c|c|}
\hline $\begin{array}{c}\text { Filler } \\
\text { material }\end{array}$ & PDMS & Parylene C & PMMA & $\mathrm{Al}_{2} \mathrm{O}_{3}$ \\
\hline $\begin{array}{c}\text { Young's } \\
\text { Modulus }\end{array}$ & $750 \mathrm{kPa}$ & $2.8 \mathrm{GPa}$ & $3 \mathrm{GPa}$ & $400 \mathrm{GPa}$ \\
\hline $\begin{array}{c}\text { Relative } \\
\text { permittivity }\end{array}$ & 2.75 & 2.95 & 3 & 5.7 \\
\hline $\begin{array}{c}\text { Dielectric } \\
\text { losses (\%) }\end{array}$ & $1^{[53]}$ & $1^{[45]}$ & $1.7^{[52]}$ & $0.05^{[54]}$ \\
\hline $\mathrm{V}_{\text {oc }}(\mathrm{mV})$ & 82.02 & 17.25 & 15.99 & 0.27 \\
\hline $\mathrm{C}_{\text {cell }}(\mathrm{F})$ & $4.83 \times 10^{-19}$ & $5.02 \times 10^{-19}$ & $5.07 \times 10^{-19}$ & $7.5 \times 10^{-19}$ \\
\hline
\end{tabular}




\begin{tabular}{|c|c|c|c|c|}
\hline (eq. 14) & & & \\
\hline $\begin{array}{r}\mathrm{R}_{\text {opt }}(\Omega) \\
\text { (eq. 16) }\end{array}$ & $6.53 \times 10^{16}$ & $6.29 \times 10^{16}$ & $6.23 \times 10^{16}$ & $4.22 \times 10^{16}$ \\
\hline $\begin{array}{r}\text { Popt }(W) \\
\text { (eq. 15) }\end{array}$ & $5.15 \times 10^{-20}$ & $2.37 \times 10^{-21}$ & $2.05 \times 10^{-21}$ & $9.17 \times 10^{-25}$ \\
\hline
\end{tabular}

Simulation results show that the single cell VING containing PDMS, which has the lowest Young's modulus (750 kPa) and permittivity (2.75), generates the highest voltage ( 4.7 times the one generated with Parylene $C$ ) and average power ( 22 times the one obtained with Parylene $\mathrm{C}$ ).

Since that above results showed that the PDMS, which has the lowest Young's modulus and permittivity, generates the highest voltage and power, HyMeSoVING method is used in order to evaluate the effect of the filler's Young's modulus and the permittivity on the VING characteristics.

For the first study, the filler's permittivity is fixed to 2.95 and only the Young's modulus is varied from $500 \mathrm{kPa}$ to $400 \mathrm{GPa}$. This range is chosen since the most used filler materials have a Young's Modulus of some GPa. ${ }^{[5,18,52,53]}$ Results are presented in Figure 4. 


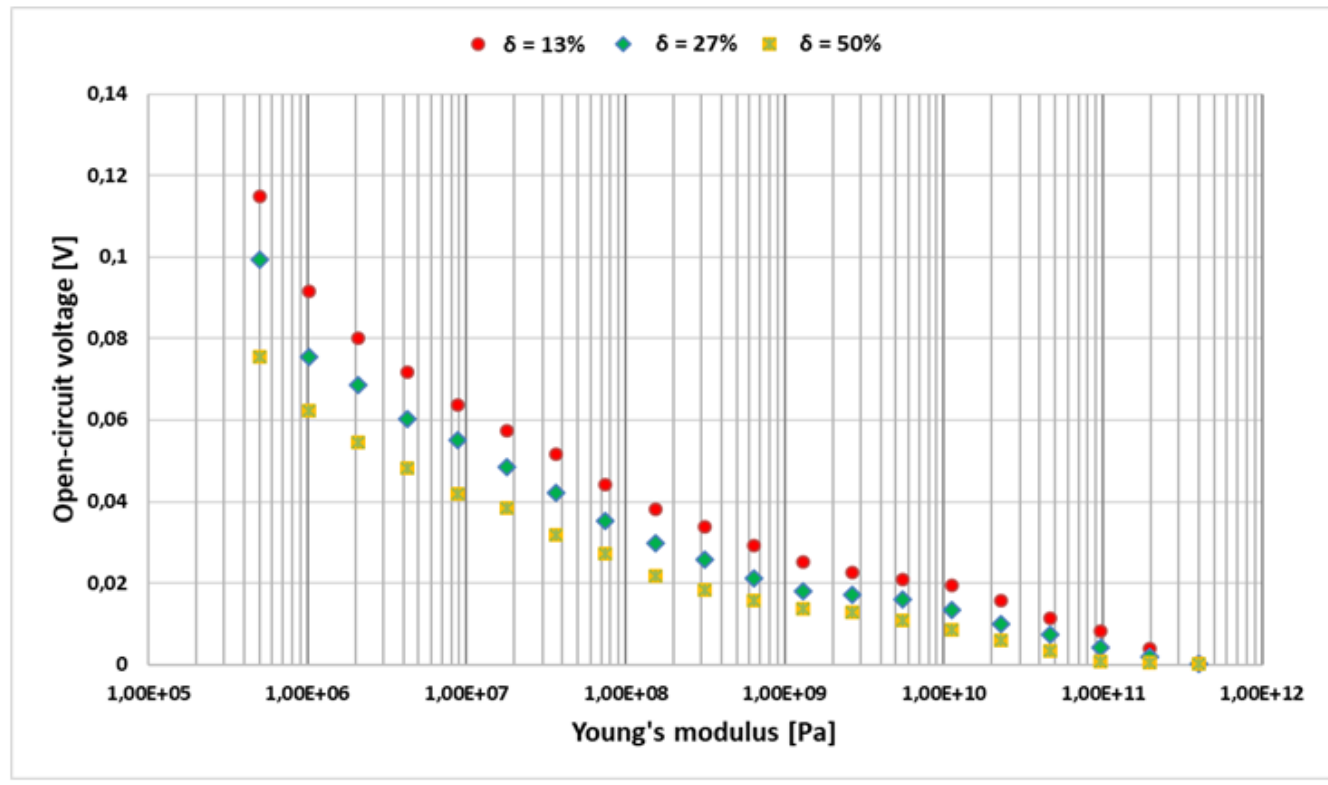

(a)

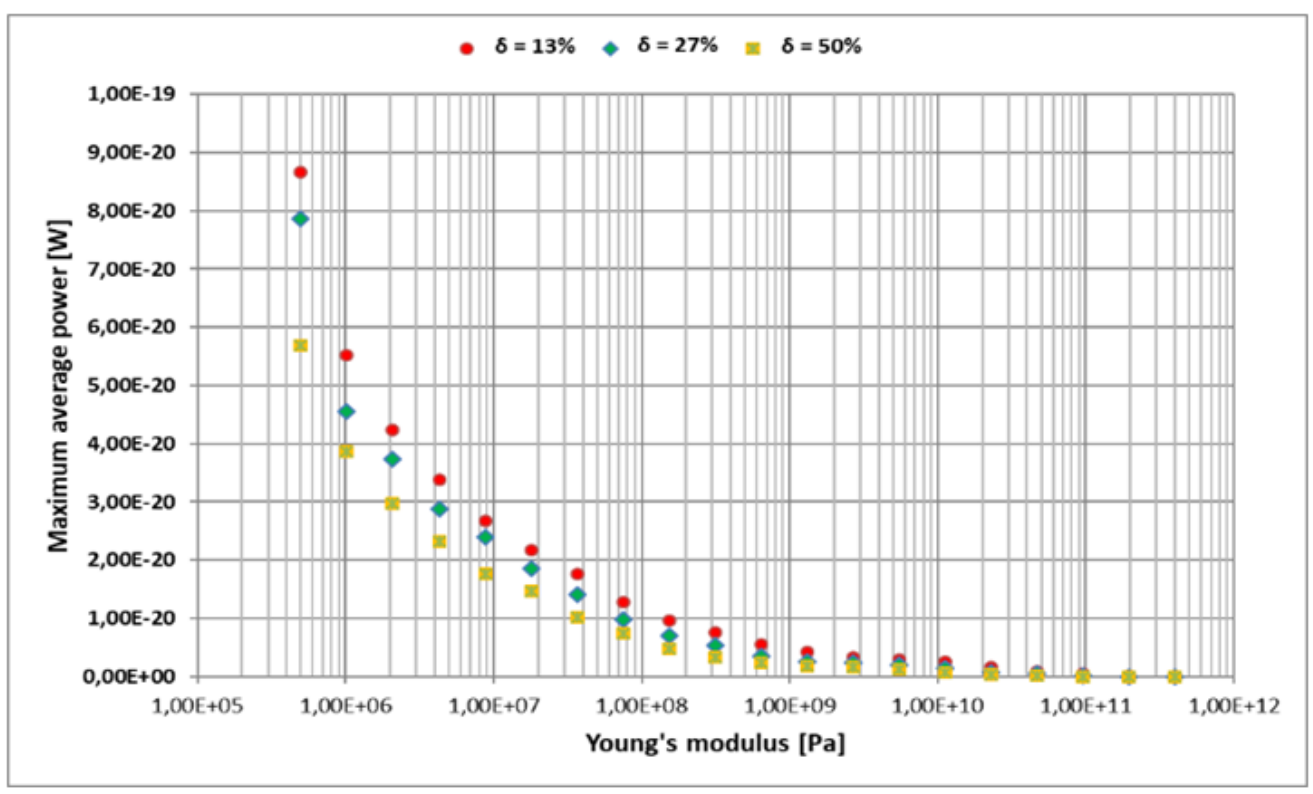

(b)

Figure 4: (a) Open-circuit voltage and (b) Maximum average power as a function of the filler Young's modulus for several ZnO volume fractions $\delta$.

Figure 4 shows that the higher the Young's modulus, the lower the generated voltage and the average power of the elementary cell. In fact, for a volume fraction of $27 \%$, the Parylene C Young's modulus (2.8 GPa) gives an open-circuit voltage $30 \%$ higher and an average power $66 \%$ higher than a material with a $10 \mathrm{GPa}$ Young's modulus. We can also observe that for a volume fraction of $13 \%$ the generated voltage and the average power are higher than the other studied volume fractions. This is because this value is close to the optimum NWs density values giving the maximum voltage (optimum density $12.5 \%$ ) and average power (optimum density $13 \%$ ). 
The second set of studies consists in fixing the filler Young's modulus to $2.8 \mathrm{GPa}$ and varying its relative dielectric permittivity from 1 to 7 , a range corresponding to the most usual filler materials. ${ }^{[5,18,52,53]}$ Results are presented Figure 5.

Figure $\mathbf{5}$ shows that the higher the permittivity, the lower the generated voltage and the average power of the elementary cell. In fact, for a volume fraction of $27 \%$, the Parylene $C$ permittivity (2.95) gives an open-circuit voltage $70 \%$ higher and an average power $64 \%$ higher than a material with a permittivity equal to 7 .

Based on all the above studies, it appears that choosing an optimal filler material with low Young's modulus and permittivity is more powerful than changing the NWs fraction.

Of course, the deposition methods of the different fillers are not the same, and the thickness of the residual layer on top of the NW is often different, which influences also the efficiency of the VING. In reference 18, the top layer is $7 \mu \mathrm{m}$ thick for PDMS deposited by spin coating, in reference 54 the top layer of spin-coated PMMA is around $1 \mu \mathrm{m}$, whereas in reference 16 this layer is $200 \mathrm{~nm}$ thick for Parylene C deposited by Chemical Vapor Deposition (CVD). A thick layer atop the NWs is expected to lower the VING performance. ${ }^{[15]}$ Changing the filler material while maintaining a thin residual layer atop the NWs is not straightforward, as it strongly depends on the process used to deposit the filler material, and on the capacity of the filler to infiltrate the NWs array. This aspect makes a comparison between different prototypes very difficult, especially since experimental testing conditions usually vary from one study to another. 


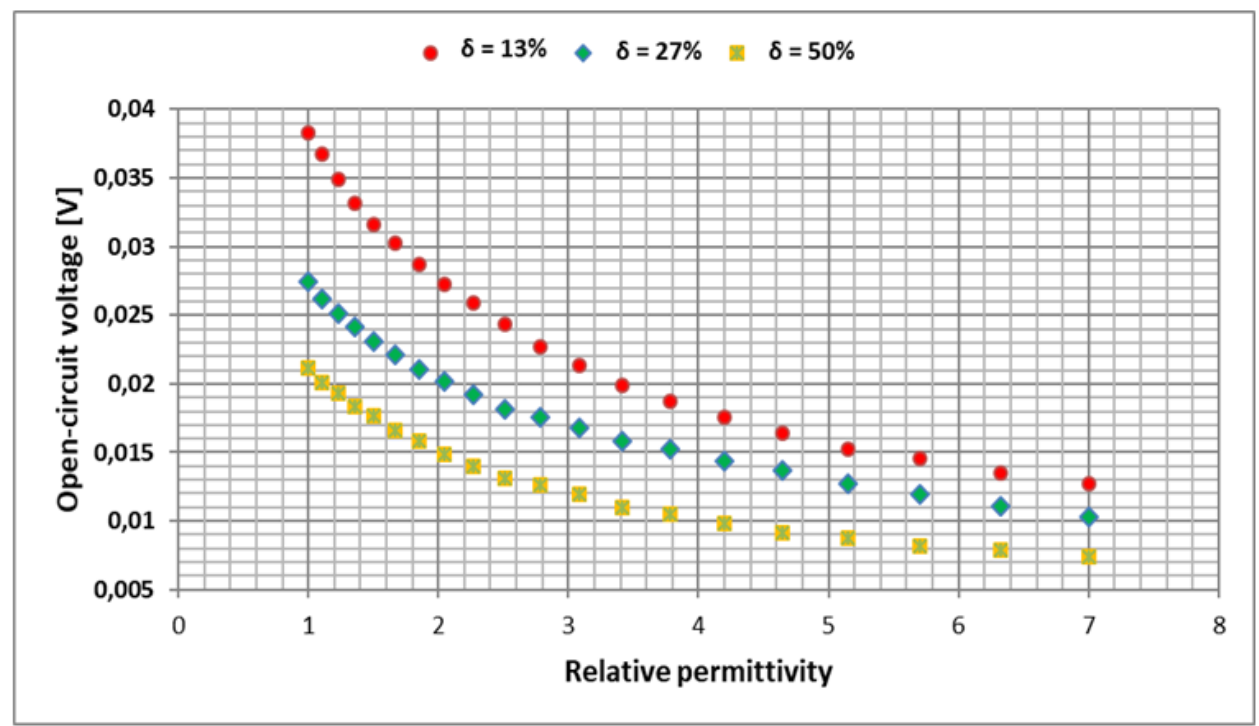

(a)

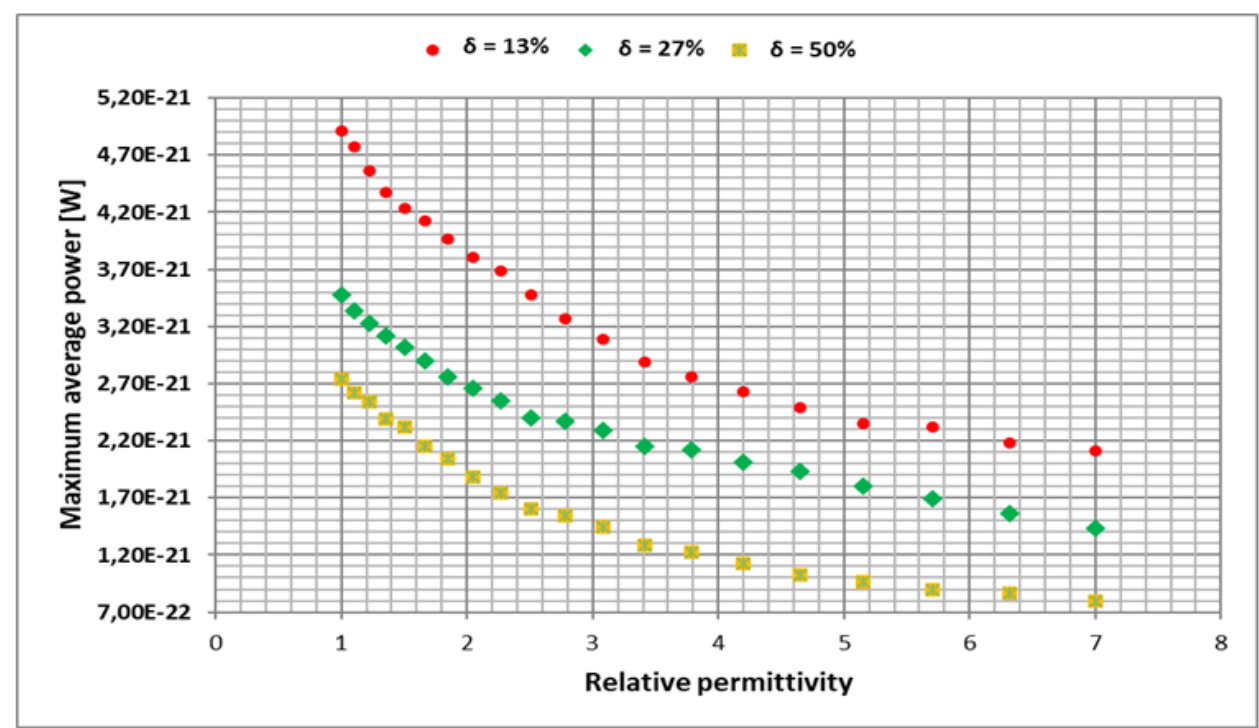

(b)

Figure 5: (a) Open-circuit voltage and (b) Maximum average power as a function of the filler relative permittivity for several $\mathrm{ZnO}$ volume fractions $\delta$.

Nevertheless, the present study demonstrates that, for a given configuration of VING (with a particular set of geometrical dimensions), the sensitivity of the VING performances on various parameters (here the NWs volume fraction and the filler mechanical and dielectric properties) is worth being quantified before performing an optimization of the various parts of the VING structure.

\section{Conclusion}

In this paper, the effect of electrical and mechanical properties (Young's modulus and dielectric permittivity) of the filler in a VING elementary cell was studied based on a previous work. ${ }^{[27]}$ Results show that a filler material with low Young's modulus and dielectric permittivity gives higher values of generated voltage and power. Among 4 
materials usually used in VING devices, PDMS which has the lower Young's modulus ( $750 \mathrm{kPa}$ ) and permittivity (2.75) is expected to provide the highest voltage (4.7 times than the one obtained with Parylene $\mathrm{C}$ ) and average power ( 22 times higher than with Parylene C) generated by the single cell. Moreover, optimizing the filler appears to have much more influence on the VING output performance than optimizing the NW's volume fraction. In further works, HyMeSoVING method will be used in order to determine which properties should have the optimal piezoelectric material in order to further improve the VING performance. The effect of the irregular length, shape and alignment of the NWs within the full NWs array will also be investigated.

\section{Acknowledgements}

This work was supported by EnSO project. EnSO has been accepted for funding within the Electronic Components and Systems For European Leadership Joint Undertaking in collaboration with the European Union's H2020 Framework Programme (H2020/2014-2020) and National Authorities [Grant agreement No. 692482].

\section{References}

[1] L. Jin, B. Zhang, L. Zhang and W. Yang, Nano Energy 2019, 66, 104086, DOI: 10.1016/j.nanoen.2019.104086.

[2] Y. Chang, J. Zuo, H. Zhang and X. Duan, Nanotechnology and Precision Engineering 2020, $3,43$.

[3] S. S. Indira , C. A. Vaithilingam , K. S. Prakash Oruganti, F. Mohd and S. Rahman, Nanomaterials 2019, 9, 773.

[4] M. Choi, G. Murillo, S. Hwang, J. W. Kim, J. H. Jung, C.-Y. Chen and M. Lee, Nano Energy 2017, 33, 462.

[5] R. Hinchet , S. Lee, G. Ardila, L. Montès, M. Mouis and Z. L. Wang, Advanced Functional Materials 2013, 24, 971.

[6] N. Gogneau, N. Jamond, P. Chrétien, F. Houzé, E. Lefeuvre and M. Tchernycheva, Semiconductor Science and Technology 2016, 31, 103002.

[7] X. Li, M. Sun, X. Wei, C. Shan and Q. Chen, Nanomaterials 2018, 8, 188.

[8] Z. L. Wang and J. Song, Science 2006, 312, 242.

[9] R. Yang, Y. Qin, L. Dai and Z. L. Wang, Nature Nanotechnology 2009, 4, 34.

[10] X. Chen, S. Xu, N. Yao and Y. Shi, Nano Letters 2010, 10, 2133.

[11] S. Xu, Y. Qin, C. Xu, Y. Wei, R. Yang and Z. L. Wang, Nature Nanotechnology 2010, 5, 366.

[12] Y. Qin, X. Wang and Z. L. Wang, Nature 2008, 451, 809.

[13] M. Lee, C.-Y. Chen, S. Wang, N. C. Cha, Y. J. Park, J. M. Kim, L.-J. Chou and Z. L. Wang, Advanced Materials 2012, 24, 1759.

[14] X. Wang, J. Song, J. Liu and Z. L. Wang, Science 2007, 316, 102.

[15] R. Hinchet, S. Lee, G. Ardila, L. Montès, M. Mouis and Z. L. Wang, Journal of Energy and Power Engineering 2013, 7, 1816.

[16] A. Dahiya, F. Morini, S. Boubenia, K. Nadaud, D. Alquier and G. Poulin-Vittrant, Advanced Materials Technologies 2017, 3, 1700249.

[17] G. Poulin-Vittrant, C. Oshman, C. Opoku, A. Dahiya, N. Camara, D. Alquier, L. P. Tran Huu Hue and M. Lethiecq, Physics Procedia 2015, 70, 909.

[18] C. Opoku, A. Dahiya, F. Cayrel, G. Poulin-Vittrant, D. Alquier and N. Camara, Royal Society of Chemistry Advances 2015, 5, 69925. 
[19] C.-T. Huang, J. Song, W.-F. Lee, Y. Ding, Z. Gao, Y. Hao, L.-J. Chen and Z. L. Wang, Journal of the American Chemical Society 2010, 132,4766.

[20] C.-Y. Chen, G. Zhu, Y. Hu, J.-W. Yu, J. Song, K.-Y. Cheng, L.-H. Peng, L.-J. Chou and Z. L. Wang, ACS Nano 2012, 6, 5687.

[21] L. Gu, N. Cui, L. Cheng, Q. Xu, S. Bai, M. Yuan, W. Wu, J. Liu, Y. Zhao, F. Ma, Y. Qin and Z. L. Wang, Nano Letters 2013, 13, 91.

[22] Y. Qi, J. Kim, T. D. Nguyen, B. Lisko, P. K. Purohit and M. McAlpine, Nano Letters 2011, 11, 1331.

[23] K.-I. Park, S. Xu, Y. Liu, G.-T. Hwang, S.-J. L. Kang, Z. L. Wang and K. J. Lee, Nano Letters, 2010, 10, 4939.

[24] Z.-H. Lin, Y. Yang, J. M. Wu, Y. Liu, F. Zhang and Z. L. Wang, The Journal of Physical Chemistry Letters 2012, 3, 3599.

[25] J. H. Jung, M. Lee, J.-I. Hong, Y. Ding, C.-Y. Chen, L.-J. Chou and Z. L. Wang, ACS Nano 2011, 5, 10041.

[26] C. Chang, V. H. Tran, J. Wang, Y.-K. Fuh and L. Lin, Nano Letters 2010, 10, 726.

[27] N. Doumit and G. Poulin-Vittrant, Advanced Theory and Simulations 2018, 1, 1800033.

[28] D. Armani, C. Liu and N. Aluru, in Technical Digest. IEEE International MEMS 99 Conference, Twelfth IEEE International Conference on Micro Electro Mechanical Systems, Orlando, USA, 1999.

[29] C. Hassler, R. P. Von Metzen, P. Ruther and T. Stieglitz, Journal of Biomedical Materials Research 2010, 93B, 266.

[30] A. Boger, K. Wheeler, A. Montalli and E. Gruskin, Journal of Biomedical materials Research - Part B - Applied biomaterials 2010, 93B, 266.

[31] M. A. El-Shahawy, Polymer testing 1999, 18, 389.

[32] J. F. Schackelford and W. Alexander, Materials Science and Engineering Handbook, Boa Raton : CRC Press 2001.

[33] A. Kachroudi, S. Basrour, L. Rufer, A. Sylvestre and F. Jomni, Smart Materials and Structures 2015, 24, 125013.

[34] A. Kahouli, A. Sylvestre, L. Ortega, F. Jomni, B. Yangui, M. Maillard, B. Berge, J. C. Robert and J. Legrand, Applied Physics Letters 2009, 94, 152901.

[35] P. R. Sreehitha, B. Durga and M. Balachandran, Materials Today: Proceedings 2020, 24, 772.

[36] P. Bandyopadhyay, M. Dwivedi, H. Krishnaswamy and P. Ghosh, Polymer 2020, 191, 122274.

[37] R. Tao, R. Hinchet, G. Ardila and M. Mouis, Journal of Physics: Conference Series 2013, 476, 012006.

[38] L.-Y. Chen and G. W. Hunter, in 2004 MRS Fall Meeting 2004, Boston.

[39] W. Martienssen and H. Warlimont, Springer Handbookof Condensed Matter and Materials Data, Germany, Springer, 2005

[40] A. Yu, H. Li, H. Tang, T. Liu, P. Jiang and Z. L. Wang, Physica Status Solidi (RRL) 2011, 5, 162.

[41] L. Lu, N. Jamond, P. Chrétien, F. Houzé, F. Travers, J. Harmand, F. Glas, F. Julien, N. Gogneau and M. Tchernycheva, Journal of Physics: Conference Series 2016, 773, 012010.

[42] H. Sun, H. Tian, Y. Yang, Y.-C. Zhang, X. Liu, S. Ma, H.-M. Zhao and T.-L. Ren, Nanoscale 2013, 5, 6117.

[43] S. Kannan, M. Parmar, R. Tao, G. Ardila and M. Mouis, Journal of Physics: Conference Series 2016, 773, 012071. 
[44] W. A. Smith and B. A. Auld, IEEE Transactions on Ultrasonics, Ferroelectrics, and Frequency Control 1991, 38, 40.

[45] N. S. Ottosen and M. Ristinmaa, The Mechanics of Constitutive Modeling, Elsevier, Sweeden 2005.

[46] C. Kärnfelt, C. Tegnander, J. Rudnicki, J. P. Starski and A. Emrich, IEEE Transactions on Microwave Theory and Techniques 2006, 54, 3417.

[47] S. Roundy, P. K. Wright and J. Rabaey, Computer Communications, 2003, 26, 1131.

[48] S. Timoshenko, D. H. Young and W. Weaver, Vibration Problems in Engineering, Wiley, New York 1974.

[49] A. Barzegar, D. Damjanovic, N. Ledermann and P. Muralt, Journal of Applied Physics 2003, 93, 4756.

[50] N. Novak, P. Keil, F. F. Schader, A. Martin, K. G. Webber and J. Rodel, Acta Materialia 2019, 162, 277.

[51] D. Yang, Y. Qiu, Q. Jiang, Z. Guo, W. Song, J. Xu, Y. Zong, Q. Feng and X. Sun, Applied Physics Letters 2017, 110, 63901.

[52] Y. Hu, L. Lin, Y. Zhang and Z. L. Wang, Advanced Materials 2012, 24, 110.

[53] S. Xu, C. Xu, Y. Liu, Y. Hu, R. Yang, Q. Yang, J.-H. Ryou, H. J. Kim, Z. Lochner, S. Choi, R. Dupuis and Z. L. Wang, Advanced Materials 2010, 42, 4749.

[54] G. Zhu, A. C. Wang, Y. Liu, Y. Zhou and Z. L. Wang, Nano Letters 2012, 12, 3086. 